\title{
Cystic fibrosis population carrier screening: 2004 revision of American College of Medical Genetics mutation panel
}

Michael S. Watson, PhD ${ }^{1, *}$ Garry R. Cutting, $M D^{2, *}$ Robert J. Desnick, MD, PhD ${ }^{3}$, Deborah A. Driscoll, $M D^{4}$, Katherine Klinger, $P h D^{5}$, Michael Mennuti, MD ${ }^{4}$, Glenn E. Palomaki ${ }^{6}$, Bradley W. Popovich, PhD ${ }^{7}$, Victoria M. Pratt, $P h D^{8}$, Elizabeth M. Rohlfs, $P h D^{9}$, Charles M. Strom, MD, PhD ${ }^{10}$, C. Sue Richards, $P h D^{11}$, David R. Witt, $M D^{12}$, and Wayne W. Grody, $M D, P h D^{+13}$

In April 2001, the American College of Medical Genetics (ACMG) Cystic Fibrosis (CF) Carrier Screening Working Group recommended a panel of mutations and variants that should be tested to determine carrier status within the CFTR gene as a part of population screening programs. ${ }^{1,2}$ This was initially done in response to the recommendations of an NIH CF Consensus Conference that CF carrier screening be considered by all couples for use before conception or prenatally. ${ }^{3} \mathrm{At}$ that time, the Working Group recognized limitations in our understanding of the population frequencies of several CF alleles and proposed to review mutation distribution data after the first two years of the program. In 2002, as part of an ongoing effort to ensure that the cystic fibrosis carrier screening programs are current with respect to the scientific literature and other available data and practices, we initiated a second review of data on the distribution of mutations in different ethnic groups and we began to assess whether providers were

\footnotetext{
From the ACMG Cystic Fibrosis Carrier Screening Work Group, ${ }^{1}$ American College of Medical Genetics, Bethesda, Maryland; ${ }^{2}$ McKusick-Nathans Institute of Genetic Medicine, Johns Hopkins University School of Medicine, Baltimore, Maryland; ${ }^{3}$ Department of Human Genetics, Mount Sinai School of Medicine, New York, New York; ${ }^{4}$ Department of Obstetrics and Gynecology, University of Pennsylvania School of Medicine, Philadelphia, Pennsylvania, ${ }^{5}$ Genzyme Corp, Framingham, Massachusetts; ${ }^{6}$ Foundation for Blood Research, Scarborough, Maine; ${ }^{7}$ Xenon Pharmaceuticals, Burnaby, British Columbia, Canada; ${ }^{8}$ Nichols Inst./ Quest Diagnostics, Chantilly, Virginia; ${ }^{9}$ Genzyme Corp., Westborough, Massachusetts; ${ }^{10} \mathrm{Ni}$ chols Inst./Quest Diagnostics, San Juan Capistrano, California; ${ }^{11}$ Molecular and Medical Genetics, Oregon Health Sciences University, Portland, Oregon; ${ }^{12}$ Kaiser Permanente, San Jose, California; ${ }^{13}$ Divisions of Medical Genetics and Molecular Pathology, UCLA School of Medicine, Los Angeles, California.

${ }^{*}$ These authors contributed equally to this article.
}

Mike Watson, ACMG, Executive Director, 9650 Rockville Pike, Bethesda, MD 20814.

Go to www.geneticsinmedicine.org for a printable copy of this document.

ACMG standards and guidelines are designed primarily as an educational resource for medical geneticists and other health care providers to help them provide quality medical genetic services. Adherence to these standards and guidelines does not necessarily ensure a successful medical outcome. These standards and guidelines should not be considered inclusive of all proper procedures and tests or exclusive of other procedures and tests that are reasonably directed to obtaining the same results. In determining the propriety of any specific procedure or test, the geneticist should apply his or her own professional judgment to the specific clinical circumstances presented by the individual patient or specimen. It may be prudent, however, to document in the patient's record the rationale for any significant deviation from these standards and guidelines.

DOI: 10.1097/01.GIM.0000139506.11694.7C experiencing challenges in delivering this service. ${ }^{4}$ The current CF Foundation patient mutation database includes nearly double the number of CF patient chromosomes available for analysis in 2000. This report summarizes the major recommendations of our Working Group with the supporting justification for these decisions. A number of articles in this issue of Genetics in Medicine provide some of the data on which our decisions were made, whereas others provide new information related to this topic.

\section{QUESTIONS ADDRESSED}

The questions addressed in this reevaluation of data were as follows:

(1) Has the observed frequency of any CF mutation changed significantly since 1999 ?

(a) Should mutations not meeting the prior standard of $>0.1 \%$ frequency in $\mathrm{CF}$ patients be removed?

(b) Should mutations that now have a frequency of $0.1 \%$ or greater but that were $<0.1 \%$ in the initial analysis be added?

(2) Is the prevalence of CF mutations in the general population the same as that predicted from their frequency in CF patients?

(3) Is there evidence of consistent and recurring challenges with interpretation of some of the mutations in the CF panel?

\section{PROCESS}

\section{Data sources}

\section{CF patients}

Multiple databases were used to determine the rates of occurrence of the various mutations in CF patients. The goal was to base decisions on a pan-ethnic United States population. CF patient population data were derived from the Cystic Fibrosis Foundation (CFF) and the Cystic Fibrosis Consortium. See Palomaki et al. ${ }^{5}$ for details on these data sets and their limitations with regard to overestimates and underestimates of allele frequencies. Analysis of the rates of $\mathrm{CF}$ patient mutations that were not included in the original ACMG 25 were based exclu- 
sively on 42,737 CF patient chromosomes provided by the CFF (personal communication, Preston Campbell, MD, Medical Director, CFF, 2004). The CFF data did not include Ashkenazim Jewish as an ethnic group.

\section{General population screening data}

Mutation status of $>400,000$ individuals screened was provided by Kaiser Permanente of Northern California, Quest Diagnostics, Laboratory Corporation of America (LabCorp), and Genzyme Genetics (data not shown). General population data are mostly derived from testing that uses the ACMG 25 mutation panel. Hence, general population data for mutations not included in that panel was limited to information provided by Genzyme Genetics and Kaiser Permanente.

\section{Organization of data}

Data were stratified by self-reported race/ethnicity when available. CF patients self-identified as either non-Hispanic Caucasian, African American, Hispanic, Asian, or other. There were 37,263 non-Hispanic Caucasian CF chromosomes, 1,350 from African Americans, 2,718 from Hispanics, 125 from Asians, and 108 from others (American Indians and Aleutians). An additional 1,173 CF chromosomes were from individuals of unknown ethnicity. A subset of patients from the general population study self-identified as either non-Hispanic Caucasian, African American, Hispanic, Asian, or American Indian/Aleutian.

\section{Mutation selection standards}

As in the initial recommendations of a CF mutation screening panel, a standard was set that a mutation should be present in at least $0.1 \%$ of CF patient chromosomes. Further, the mutations chosen should be associated with classical CF rather than with milder phenotypes because the decision-making process largely impacts reproductive decisions.

\section{Revising the CF carrier screening panel}

Table 1 lists the mutations found in CF patient chromosomes in descending order of their occurrence in a pan-ethnic population. Mutation frequencies are listed by ethnic group to provide laboratories testing local populations with data to determine an appropriate mutation panel for their test population.

\section{Has the observed frequency of any CF mutation changed} significantly since 1999?

$1078 \mathrm{delT}$ was found to occur in $0.03 \%$ of CF cases in the current analysis.

Technical issues of removing a mutation from a panel, from the perspective of assay platform development, are thought to be minimal. Although there may be other issues associated with changing a "standard," it was felt that changes should be implemented on the basis of the substantially enlarged data set available to the Working Group. It was decided that any mutation that has prevalence $<0.1 \%$ should be removed from the screening panel, but that henceforth, decisions would be based on the benefits and costs of incremental gain in the perfor- mance characteristics of the screening test as defined here. Thus, the ACMG recommends that 1078delT be removed from the panel.

Six mutations not included in the original panel occurred at frequencies ranging from $0.1 \%$ to $0.17 \%$ in CF patients in the 2003 data (Table 2). Together the six could account for approximately $0.77 \%$ of $\mathrm{CF}$ alleles.

Several issues arise when considering adding mutations to a carrier screening mutation panel. We chose to give minimal consideration to the adaptability of current testing platforms. Rather, we focused on improved clinical utility and have previously addressed issues of analytical quality. ${ }^{6}$ We also weighed the incremental gain that would be achieved by adding these six mutations against the potential increase in cost and errors associated with the changes. ${ }^{7}$ The Working Group recommends no additions to the general population screening panel be made at this time. Additions may be considered in the future as more data become available for different ethnic groups or as new technologies emerge. The Working Group recognizes that local demographics may suggest the need to add mutations specific to some groups or to compress the panel to an ethnic-specific subset as was stated in the original recommendations. Table 2 shows the rates of occurrence of an additional 14 of the 53 mutations for which data were available. These 14 mutations occurred in $0.01 \%$ to $0.09 \%$ of CF patient chromosomes and may be considered when supplementing our recommended panel to improve its sensitivity in other ethnic groups. However, their relationship to disease severity was not assessed in our analysis.

Is the prevalence of CF mutations in the general population the same as that predicted from their frequency in CF patients?

The mutation/variant I148T occurs at rates 50 to 100 times higher than in the general population being tested for carrier status than in patients. ${ }^{8,9}$ It was shown that CFTR genes bearing I148T in CF patients have a second mutation termed 3199del6. The vast majority of individuals in the general population with I148T do not have the 3199del6 mutation. Several lines of evidence indicate that 3199del6 is the disease causing mutation. One, CF patients have been described who lack I148T but have 3199 del6 in association with another CF causing mutation. ${ }^{10}$ Two, unaffected individuals have been described who have a CF mutation associated with severe CF and I148T but lacking 3199del6..$^{7-11}$

Because the frequency of I148T alone is $0.05 \%$ and I $148 \mathrm{~T}$ with 3199del6 in this analysis is considerably lower than $0.1 \%$ and because I148T does not cause classical CF by itself, we recommend removing I148T from the CF carrier screening panel. The rarity of $3199 \mathrm{del} 6$ does not support its addition to the panel as a disease associated mutation and we recommend against it being added as a reflex test for carrier testing.

\section{Is there evidence of consistent and recurring challenges with} interpretation of some of the mutations in the CF panel?

$\mathrm{R} 117 \mathrm{H}$ was considered problematic in interpretation due to the complexity of its association with the $5 \mathrm{~T} / 7 \mathrm{~T} / 9 \mathrm{~T}$ variant and others have suggested that it may not be appropriate for carrier screen- 
Table 1

CFTR mutation frequency among individuals with clinically diagnosed cystic fibrosis by racial/ethnic group and in a pan-ethnic U.S. population

\begin{tabular}{|c|c|c|c|c|c|c|}
\hline \multirow[b]{2}{*}{ CFTR mutation } & \multicolumn{6}{|c|}{ Mutation frequency among individuals with clinically diagnosed cystic fibrosis (\%) } \\
\hline & $\begin{array}{l}\text { Non-Hispanic } \\
\text { Caucasian }\end{array}$ & $\begin{array}{l}\text { Hispanic } \\
\text { Caucasian }\end{array}$ & $\begin{array}{l}\text { African } \\
\text { American }\end{array}$ & $\begin{array}{c}\text { Asian } \\
\text { American }\end{array}$ & $\begin{array}{l}\text { Ashkenazi } \\
\text { Jewish }\end{array}$ & $\begin{array}{l}\text { Pan-Ethnic } \\
\text { Population }^{5}\end{array}$ \\
\hline delF508 & 72.42 & 54.38 & 44.07 & 38.95 & 31.41 & 66.31 \\
\hline G542X & 2.28 & 5.10 & 1.45 & 0.00 & 7.55 & 2.64 \\
\hline W1282X & 1.50 & 0.63 & 0.24 & 0.00 & 45.92 & 2.20 \\
\hline G551D & 2.25 & 0.56 & 1.21 & 3.15 & 0.22 & 1.93 \\
\hline $621+1 G>T$ & 1.57 & 0.26 & 1.11 & 0.00 & 0.00 & 1.30 \\
\hline N1303K & 1.27 & 1.66 & 0.35 & 0.76 & 2.78 & 1.27 \\
\hline R553X & 0.87 & 2.81 & 2.32 & 0.76 & 0.00 & 1.21 \\
\hline dell507 & 0.88 & 0.68 & 1.87 & 0.00 & 0.22 & 0.90 \\
\hline $3849+10 \mathrm{kbC}>\mathrm{T}$ & 0.58 & 1.57 & 0.17 & 5.31 & 4.77 & 0.85 \\
\hline $3120+1 \mathrm{G}>\mathrm{T}$ & 0.08 & 0.16 & 9.57 & 0.00 & 0.10 & 0.86 \\
\hline $\mathrm{R} 117 \mathrm{H}$ & 0.70 & 0.11 & 0.06 & 0.00 & 0.00 & 0.54 \\
\hline $1717-1 \mathrm{G}>\mathrm{T}$ & 0.48 & 0.27 & 0.37 & 0.00 & 0.67 & 0.44 \\
\hline $2789+5 \mathrm{G}>\mathrm{A}$ & 0.48 & 0.16 & 0.00 & 0.00 & 0.10 & 0.38 \\
\hline R347P & 0.45 & 0.16 & 0.06 & 0.00 & 0.00 & 0.36 \\
\hline $711+1 \mathrm{G}>\mathrm{T}$ & 0.43 & 0.23 & 0.00 & 0.00 & 0.10 & 0.35 \\
\hline R334W & 0.14 & 1.78 & 0.49 & 0.00 & 0.00 & 0.37 \\
\hline R560T & 0.38 & 0.00 & 0.17 & 0.00 & 0.00 & 0.30 \\
\hline R1162X & 0.23 & 0.58 & 0.66 & 0.00 & 0.00 & 0.30 \\
\hline 3569delC & 0.34 & 0.13 & 0.06 & 0.00 & 0.00 & 0.28 \\
\hline A455E & 0.34 & 0.05 & 0.00 & 0.00 & 0.00 & 0.26 \\
\hline G85E & 0.29 & 0.23 & 0.12 & 0.00 & 0.00 & 0.26 \\
\hline 2184delA & 0.17 & 0.16 & 0.05 & 0.00 & 0.10 & 0.15 \\
\hline $1898+1 \mathrm{G}>\mathrm{A}$ & 0.16 & 0.05 & 0.06 & 0.00 & 0.10 & 0.13 \\
\hline $1148 \mathrm{~T}$ & 0.09 & 0.09 & 0.05 & 0.00 & 0.10 & 0.08 \\
\hline 1078delT & 0.02 & 0.09 & 0.00 & 0.00 & 0.00 & 0.03 \\
\hline Total & 88.40 & 71.90 & 64.51 & 48.93 & 94.14 & 84.00 \\
\hline
\end{tabular}

ing. ${ }^{12}$ Based on assessment of this situation, the Working Group decided that interpretive problems would have been avoided if $5 \mathrm{~T}$ had been tested only as a reflex to a finding of $\mathrm{R} 117 \mathrm{H}$, as originally recommended. Furthermore, individuals with $\mathrm{R} 117 \mathrm{H}$ and $5 \mathrm{~T}$ are at risk of having offspring with $\mathrm{CF}$ if their partner is also a CF carrier and should be counseled accordingly. Phasing of these sequence changes may be uncertain and these patients may benefit from genetic counseling to discuss the risk and prenatal testing options. Because the frequency of $\mathrm{R} 117 \mathrm{H}-5 \mathrm{~T}$ is appreciable, the Working Group recommends retaining R117H, whereas emphasizing the need to perform a screening test for $5 \mathrm{~T}$ only as a reflex when $\mathrm{R} 117 \mathrm{H}$ is present.

\section{DISCUSSION}

In addition to the issues already discussed, several related issues have been raised by others. Warner et al. ${ }^{12}$ suggest that it is inappropriate to screen for mutations such as $\mathrm{R} 117 \mathrm{H}$ for which a definitive prediction of clinical outcome can not be provided. With appropriate informed consent, the limitations inherent in predicting specific phenotypes resulting from any mutations in a CF carrier screening panel should be discussed. Although our recommendations are pertinent to classical CF risk rather than the milder phenotypes discussed, there are some mutations that may be associated with mild or severe forms of CF depending on the mutations with which they are paired, thereby complicating the process of selecting mutation panels. A goal of informed consent for CF carrier testing is to make couples aware that there is a range of clinical outcomes that cannot be predicted, and that that, in and of itself, constitutes informed consent.

An additional issue that may be amenable to the informed consent process is the reporting of results. It has been ar- 
Table 2

\begin{tabular}{|c|c|c|c|c|c|c|}
\hline & $\begin{array}{l}\text { Non-Hispanic } \\
\text { Caucasian }\end{array}$ & $\begin{array}{c}\text { African } \\
\text { American }\end{array}$ & Hispanic & Asian & Other & Total \\
\hline \multicolumn{7}{|c|}{ Distribution of additional mutations not in original ACMG 25 now appearing in $>0.1 \%$ CF patient chromosomes (\%) } \\
\hline Q493X & 0.19 & 0.07 & 0.04 & 0 & 0 & 0.17 \\
\hline S549N & 0.05 & 0.8 & 0.66 & 3.2 & 0.60 & 0.14 \\
\hline 3905 ins T & 0.13 & 0.07 & 0.04 & 0 & 0 & 0.12 \\
\hline E60X & 0.13 & 0 & 0.11 & 0 & 0 & 0.12 \\
\hline Y1092X & 0.11 & 0.15 & 0.26 & 0 & 0 & 0.12 \\
\hline 2183 delAA- $>$ G & 0.11 & 0 & 0 & 0 & 0 & 0.10 \\
\hline \multicolumn{7}{|c|}{ Distribution of additional mutations not in original ACMG 25 appearing in $0.01 \%-0.1 \%$ of CF patient chromosomes (\%) } \\
\hline R1158X & 0.07 & 0.74 & 0.15 & 0 & 0 & 0.09 \\
\hline V520F & 0.09 & 0 & 0.04 & 0.8 & 0 & 0.09 \\
\hline $\mathrm{R} 347 \mathrm{H}$ & 0.06 & 0 & 0 & 1.6 & 0 & 0.06 \\
\hline A559T & 0 & 1.41 & 0 & 0 & 0 & 0.04 \\
\hline D1270N & 0.02 & 0.15 & 0.26 & 0 & 0 & 0.04 \\
\hline R1066C & 0.02 & 0.07 & 0 & 0 & 0 & 0.03 \\
\hline D1152H & 0.03 & 0 & 0.11 & 0 & 0 & 0.03 \\
\hline 3876delA & 0 & 0 & 0.48 & 0 & 0 & 0.03 \\
\hline W1089X & 0 & 0 & 0.52 & 0 & 0 & 0.03 \\
\hline 2307insA & 0 & 0.67 & 0.07 & 0 & 0 & 0.03 \\
\hline G330X & 0 & 0.52 & 0.04 & 0 & 0 & 0.02 \\
\hline $1812-1 \mathrm{G}->\mathrm{A}$ & 0 & 0.44 & 0.04 & 0 & 0 & 0.02 \\
\hline $405+3 \mathrm{~A}->\mathrm{C}$ & 0 & 0.29 & 0 & 0 & 0 & 0.01 \\
\hline Q890X & 0 & 0 & 0.18 & 0 & 0 & 0.01 \\
\hline
\end{tabular}

gued that a laboratory is obligated to report any and all information that is gleaned from a test system, however, there is no regulatory requirement and practice varies. Because the CF mutation testing platforms included the reflex tests this led to the reporting of the $5 \mathrm{~T}$ allele in the absence of $\mathrm{R} 117 \mathrm{H}$ by some laboratories. It is not an uncommon practice for clinical chemistry testing platforms to bundle many analytes into a single test but it poses a dilemma for laboratories. Laboratories using existing reagents and tests may be uncomfortable not reporting the 5T/7T/9T alleles and sequences that are no longer considered appropriate for CF carrier screening. The informed consent process should emphasize that CF carrier screening is not designed to detect all of the mutations that cause classical CF or the milder phenotypes. As a result of this process, specification of which results would be reported may help laboratories decide to only report the test results that comprise the recommended panel. However, this may be difficult to implement.

CF carrier screening is among the first general population genetic screening tests. Our experience with CF carrier screening offers a potential prototype for the development of other genetic screening programs. Recent experience with I148T serves to demonstrate the importance of evaluating distribution among both affected and carrier screening populations to discern discrepancies before inclusion in a screening panel.

Approved by the Board of Directors of the American College of Medical Genetics on March 3, 2004.

(C) AMERICAN COLLEGE OF MEDICAL GENETICS, 2004.

\section{References}

1. Grody WW, Cutting GR, Klinger KW, Richards CS, Watson MS, Desnick RJ. Laboratory standards and guidelines for population-based cystic fibrosis carrier screening. Genet Med 2001;3:149-154.

2. American College of Obstetricians and Gynecologists, and American College of Medical Genetics. Preconception and prenatal carrier screening for cystic fibrosis. Clinical and Laboratory Guidelines. American College of Obstetricians and Gynecologists, Washington, DC; 2001.

3. NIH Consensus Development Conference Statement. Genetic testing for cystic fibrosis. April 14-16, 1997. Arch Intern Med 1999;159:1529-1539.

4. Watson MS, Grody WW, Mennuti MT, Popovich BW, Richards CS. Cystic fibrosis carrier screening: Issues in Implementation. Genet Med 2003;4/6:407-409.

5. Palomaki GE, Fitzsimmons S, Haddow JE. Clinical sensitivity of prenatal screening for cystic fibrosis via CFTR carrier testing in a United States Pan-Ethnic Population. Genet Med (in press in this issue)

6. Richards CS, Bardley LA, Amos J, Allitto B, Grody WW, Maddalena A et al. Technical Standards and Guidelines for CFTR mutation testing. Genet Med 2002;4:379-391.

7. Haddow JE and Palomaki GE. Population-based prenatal screening for cystic fibrosis via carrier testing: ACCE review. 2002. Available at: http://www.cdc.gov/genomics/activities/FBR/ACCE.htm. Accessed 
8. Rohlfs EM, Zhou Z, Sugarman EA, Heim EI, Pace RG, Knowles MR et al. I148T CFTR mutation confers a variable phenotype and occurs on multiple haplotypes. Am Jour Hum Genet Suppl 2001:69A.

9. Rohlfs EM, Zhou Z, Sugarman EA, Heim EI, Pace RG, Knowles MR et al. The I148T CFTR allele occurs on multiple haplotypes: A complex allele is associated with cystic fibrosis. Genet Med 2002;4:319-323.

10. Strom CM, Huang D, Buller A, Redman J, Crossley B, Anderson B et al. Cystic fibrosis screening using the College panel: Platform comparison and lessons learned from the first 20,000 samples. Genet Med 2002;4:289-296.

11. Buyse IM, McCarthy SE, Lurix P, Pace RA, Vo D, Bartlett GA et al. Use of MALDITOF mass spectrometry in a 51-mutation test for cystic fibrosis: evidence that 3199del6 is a disease causing mutation. Genet Med 2004;6:426-430.

12. Warner JP, Gilfillan AJ, Porteous DJ, Porteous ME. Fibrosis mutation R117H is not an appropriate antenatal screening mutation. Unpublished data, 2004. 